Available online on 15.11.2020 at http://ujpr.org
Universal Journal of Pharmaceutical Research
An International Peer Reviewed Journal
Open access to Pharmaceutical research

\title{
RADIOGRAPHIC ASSESSMENT OF THE COURSE AND VISIBILITY OF THE MANDIBULAR CANAL BY PANORAMIC RADIOGRAPHY Nashwan Yahya A Al-Shamahi ${ }^{1}{ }^{\mathbb{D}}$, Al-Kasem Mohammed Abbas ${ }^{2}{ }^{\circ}$, Hassan Abdulwahab

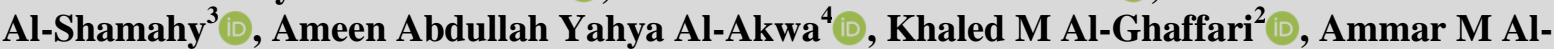 Mortada $^{2}$, Mohammed A Al-labani ${ }^{4}(\mathbb{D}$ \\ ${ }^{\prime}$ Medicine Department, Faculty of Medicine and Health Sciences, Sana'a University, Republic of Yemen. ${ }^{2}$ Department of Maxillo-Facial, Faculty of Dentistry, Sana'a University, Republic of Yemen. ${ }^{3}$ Department of Basic Sciences, Faculty of Dentistry, Sana'a University, Republic of Yemen. ${ }^{4}$ Orthodontics, Pedodontics and Prevention Department Faculty of Dentistry, Sana'a University, Yemen.
}

\section{ABSTRACT}

Background and Objectives: The mandibular canal is a canal inside the mandible that contains the inferior alveolar artery, the inferior alveolar nerve and the inferior alveolar vein. The anatomy and variations of the human mandible are very important for planning various surgical measures such as extraction of the third molar, dental implants and mandibular reconstruction. This study was conducted to determine the frequency of the different courses of the mandibular canal and to investigate the visibility of the mandibular canal by panoramic radiography, among a sample of Yemeni adults.

Subjects and Methods: A retrospective cross-sectional study was conducted in Sana'a city on a sample of Yemeni adults. The study consisted of panoramic radiographs of 928 patients; the number of males was $340(36.6 \%)$ and 588 females (63.4\%). The mandibular canal course, as shown in the panoramic radiographs, was classified into four types: elliptical, linear, turning curves and spoon-shaped. The visibility of this canal from the first to the third molar region was assessed through visual determination of whether the lower canal was clearly visible, possibly visible, or invisible.

Results: Elliptical curves were the most observed along the mandibular canal course at $62.2 \%$ of the total, followed by the linear curve $(24.8 \%)$ while the lower rate curve spoon $(7.9 \%)$ and the turning curve $(5.2 \%)$. There were no statistically considerable differences between the distribution of the mandibular canal courses between males and females except in the spoon curve where the ratio was $10.8 \%$ in males versus $6.1 \%$ in females $(p<0.05)$. The percentage of clearly visible mandibular canals was the highest among the spoon-shaped curves $(49.9 \%$ in the first molar, $63 \%$ in the second, $78.1 \%$ in the third molar) and the lowest among the linear curves (10.9\% in the first, $18.7 \%$ in the second and $33.5 \%$ in the third molar). On panoramic radiographs, the invisible mandibular canals are found in $198(21.3 \%)$ of the examined sites in the first molar region, in $85(11 \%)$ in the second molar region, and in only $6(0.64 \%)$ in the third molar region.

Conclusion: It was observed that elliptical curves along the path of the mandibular canal were the most present, while a decrease in the ratio of the two types of spoon curve and turning curve was observed. It was found that spoon curve was significantly more common among males than females. It was also found that the visibility of madibular canal is fewer in the first molar region than in the third molar region.

Keywords: Inferior Alveolar, Mandible, Nerve, Panoramic, Radiography.

Article Info: Received 28 August 2020; Revised 1 October; Accepted 4 November, Available online 15 November 2020

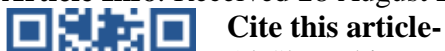

WHa Al-Shamahi NYA, Abbas Al-Kasem M, Al-Shamahy HA, Al-Akwa AAY, Al-Ghaffari KM, Al-Mortada AM, Al-labani MA. Radiographic assessment of the course and visibility of the mandibular canal by panoramic radiography. Universal Journal of Pharmaceutical Research 2020; 5(5):17-20.

DOI: https://doi.org/10.22270/ujpr.v5i5.481

Address for Correspondence

Dr. Hassan Abdul Wahab Al-Shamahy, Department of Basic Sciences, Faculty of Dentistry, Sana'a University, Republic of Yemen, Tel: +967-770299847, E-mail: shmahe@yemen.net.ye

\section{INTRODUCTION}

Inside the mandible is the mandibular canal, which is a canal that contains the inferior alveolar artery, the inferior alveolar vein and the inferior alveolar nerve. It runs obliquely down and forward to the branch, then forward laterally to the body, where it is placed under the alveoli and communicates with it all through small openings. On reaching the incisive teeth, it turns back to connect with the mental foramen, giving rise to a small canal known as the mandibular incisive canal, which extends into the cavities containing the incisor 
teeth $^{1}$. The mandibular canal is fairly close to the tops of the second molar in $50 \%$ of the radiographs. In $40 \%$ the canal is distant from the root apices, and in only $10 \%$ of the radiographs, the root crests appeared to penetrate the canal. In root canal treatment of the second molar, care must be taken to extend the perforator expander or root canal filling material because there is a potential risk of injury to the inferior alveolar nerve ${ }^{1-4}$. The mandibular canal is an important milestone to consider before performing any posterior mandibular surgery ${ }^{2-4}$. The precise location of the mandibular canal can be provided by radiological diagnosis before surgery and therefore prevent complications during any surgical procedures ${ }^{5}$. The mandibular canal pathway has been investigated in several studies, and frequent anatomical differences have been found in the intrabony course of the inferior alveolar nerve $\mathrm{e}^{6-8}$. Moreover, the radial profile of the mandibular canal can be alterable ${ }^{9}$. The mandibular canal visibility may vary significantly ${ }^{10-12}$. Wadu et al., discovered that in an adequate number of cases, the radiopaque boundaries are disrupted in radiographs, and it is invisible in some other cases. The mandibular canal typically consists of a thin trabecular bone including many circumferential spaces, and there is a fine layer of cortical bone in just a few of the mandibles ${ }^{13,14}$. Recently, Ozturk and colleagues' study ${ }^{15}$ and Liu colleagues' ${ }^{16}$ classified the mandibular canal pathway into linear, spoon-shaped, elliptic, and turning curve types (Figure 1).

In panoramas, the mandibular canal is usually observed as a definite radiopaque area, lined with a radiopaque superior and inferior boundaries ${ }^{5}$. Understanding the anatomical contrast of the pathway and the visibility of the mandibular canal will be helpful in planning treatment for procedures concerning the posterior mandible ${ }^{15}$. This study was conducted to determine the frequency of the different courses of the mandibular canal and to investigate the visibility of the mandibular canal by panoramic radiography, among a sample of Yemeni adults.

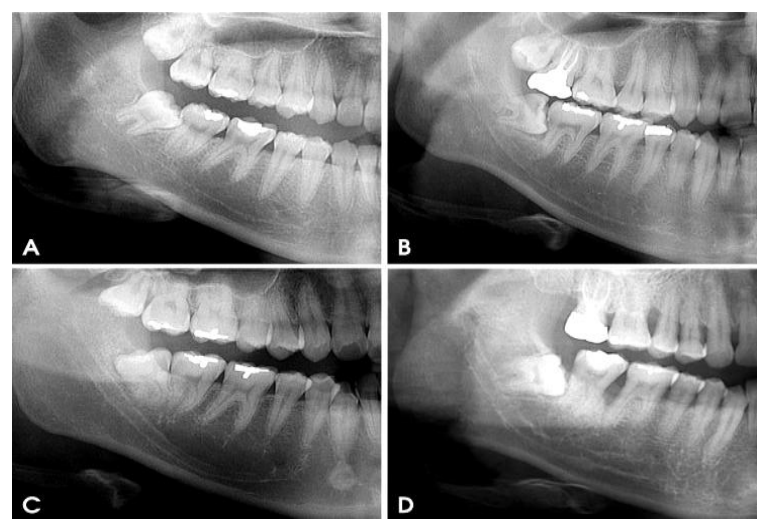

Figure 1: Classifications of the course of the mandibular canal on panoramic radiographs: A- Linear curve, the canal curve is approximately a straight line; B- Elliptic curve, the curve is approximately symmetrical; C- Spoonshaped curve, the canal has an approximate spoon shape that is similar to an asymmetric elliptic arc; and D-Turning curve, the course is unsmooth and has a turning point ${ }^{16}$.

\section{SUBJECTS AND METHODS}

The samples in this retrospective study were randomly assigned from patients who visited Ammar Dental Clinics and undertaken panoramic radiography in 2019, up to September 2020. The panoramic radiograph was done as part of the clinical diagnostic process for various causes, as extraction of the third molar and implant placement and or, orthodontic treatment planning. The number of subjects was 588 females and 340 males, with a mean age of 27.3 years and the age range was 20-58 years. Patients with mandibular disease were excluded from the study. Using Proline $\mathrm{XC}$ panoramic radiographs were taken for all. These images were carefully examined by the first investigator. The mandibular canal course was classified, as in the published research by Liu et al., ${ }^{16}$ where they classified them into four types: elliptic, linear turning curves and spoon-shaped (Figure $1^{16}$ ). Mandibular canal vision was assessed by visually decisive whether the maxillary canal is obviously visible, possibly visible, or invisible on panoramic radiographs. Wilcoxon's ranking test was used using online calculators. The Wilcoxon signed-rank test was used using online calculators to recognize statistically significant differences in the visibility of the mandibular canal between the right and the left sides. The Wilcoxon signed-rank test is a non-parametric statistical hypothesis test utilized to contrast two related samples, matching samples, or repeated measurements on a single sample to measure whether the ranks of the norm population differ (i.e. it is a paired difference test). To visualize this duct according to the course of the canal and the difference in visibility in the three mandibular regions, the Kruskal Wallis test was used. A $p$ value of less than 0.05 was considered to indicate a statistically significant difference.

\section{Ethical approval}

Ethical approval was taken from the Medical Research and Ethics Committee of the Faculty of Medicine \& Health Sciences at Sana'a University. All data, including patient identification and X-rays, were kept confidential. 


\section{RESULTS}

Elliptical curves (Figure 1-B) were the most observed along the mandibular canal course at $62.2 \%$ of the total, followed by the linear curve (Figure 1-A) $(24.8 \%)$ while the lower rate curve spoon (Figure 1-C) $(7.9 \%)$ and the turning curve (Figure 1-D) (5.2\%). There were no statistically significant differences between the distribution of the mandibular canal courses between males and females except in the spoon curve where the ratio was $10.8 \%$ in males versus $6.1 \%$ in females $(p<0.05)$. The percentage of clearly visible mandibular canals was the highest among the spoonshaped curves $(49.9 \%$ in the first molar, $63 \%$ in the second, $78.1 \%$ in the third molar) and the lowest among the linear curves $(10.9 \%$ in the first, $18.7 \%$ in the second and $33.5 \%$ in the third molar). In panoramic radiographs, invisible mandibular canals were found in $198(21.3 \%)$ of the examined sites in the first molar region, in $85(11 \%)$ in the second molar region, and in only $6(0.64 \%)$ in the third molar region.

Table 1: Frequency of the course of the mandibular canal on panoramic radiographs.

\begin{tabular}{ccccccccccc}
\hline & \multicolumn{2}{c}{ Linear curve } & \multicolumn{2}{c}{ Elliptic curve } & \multicolumn{2}{c}{ Spoon curve } & \multicolumn{2}{c}{ Turning curve } & \multicolumn{2}{c}{ Total } \\
\hline Sex & $\mathrm{N}$ & $\%$ & $\mathrm{~N}$ & $\%$ & $\mathrm{~N}$ & $\%$ & $\mathrm{~N}$ & $\%$ & $\mathrm{~N}$ & $\%$ \\
Male & 73 & 21.5 & 211 & 62.1 & 37 & $10.8^{*}$ & 19 & 5.6 & 340 & 36.6 \\
Female & 157 & 26.7 & 366 & 62.2 & 36 & $6.1^{*}$ & 29 & 4.9 & 588 & 63.4 \\
Total & 230 & 24.8 & 577 & $* 62.2$ & 73 & 7.9 & 48 & 5.2 & 928 & 100 \\
\hline
\end{tabular}

Table 2: Relationship between the course and the visibility of the mandibular canal on panoramic radiographs.

\begin{tabular}{|c|c|c|c|c|c|c|c|c|c|c|c|}
\hline & \multicolumn{2}{|c|}{ Linear curve } & \multicolumn{2}{|c|}{ Elliptic curve } & \multicolumn{2}{|c|}{ Spoon curve } & \multicolumn{2}{|c|}{ Turning curve } & \multicolumn{2}{|c|}{ Total } \\
\hline & & $\mathbf{N}$ & $\%$ & $\mathbf{N}$ & $\%$ & $\mathbf{N}$ & $\%$ & $\mathbf{N}$ & $\%$ & $\mathbf{N}$ & $\%$ \\
\hline \multirow{4}{*}{$\begin{array}{l}\text { First molar } \\
\text { region }\end{array}$} & $\begin{array}{c}\text { Visibility of } \\
\text { mandibular canal }\end{array}$ & & & & & & & & & & \\
\hline & Invisible & 61 & 26.5 & 121 & 17.3 & 9 & 12.3 & 7 & 14.5 & 198 & 21.3 \\
\hline & Probably visible & 144 & 62.6 & 399 & 69.2 & 29 & 39.7 & 33 & 68.8 & 605 & 65.2 \\
\hline & Clearly visible & 25 & 10.9 & 57 & 9.9 & 35 & 47.9 & 8 & 16.7 & 125 & 13.5 \\
\hline \multirow{3}{*}{$\begin{array}{c}\text { Second } \\
\text { molar region }\end{array}$} & Invisible & 30 & 13 & 49 & 8.5 & 0 & 0 & 6 & 12.5 & 85 & 9.2 \\
\hline & Probably visible & 157 & 68.2 & 443 & 76.8 & 27 & 37 & 37 & 77.1 & 664 & 71.6 \\
\hline & Clearly visible & 43 & 18.7 & 85 & 14.7 & 46 & 63 & 5 & 10.4 & 179 & 19.3 \\
\hline \multirow{4}{*}{$\begin{array}{l}\text { Third molar } \\
\text { region }\end{array}$} & Invisible & 5 & 2.2 & 1 & 0.17 & 0 & 0 & 0 & 0.0 & 6 & 0.64 \\
\hline & Probably visible & 148 & 64.3 & 292 & 50.6 & 16 & 21.9 & 30 & 62.5 & 486 & 52.4 \\
\hline & Clearly visible & 77 & 33.5 & 284 & 49.2 & 57 & 78.1 & 18 & 37.5 & 436 & 47 \\
\hline & Total & 230 & 100 & 577 & 100 & 73 & 100 & 48 & 100 & 928 & 100 \\
\hline
\end{tabular}

\section{DISCUSSION}

In this study, the mandibular canal course was examined using panoramic radiographs, the canal visibility was assessed, and current results illustrated the contrast and visualization of the canal course. Kieser JA et al., Bertl et al., and Heasman ${ }^{7,8,17}$ classified the mandibular canal course according to vertical locations inside the mandible, such as high, low and intermediate locations. In a study by Heasman ${ }^{17}$ using 96 normal films of the dry mandible, it showed that the majority $(68 \%)$ of the inferior canals passed along an intermediate pathway ${ }^{17}$. Ozturk et al., in $2012^{15}$ restricted classification to the canal's course in the mandibular body: catenary-like configuration $(51.1 \%)$, straight projection $(12.2 \%)$, and progressive descent from posterior to anterior $(36.7 \%)$. Also, Ozturk and colleagues' study ${ }^{15}$ classified the mandibular canal pathway into spoon-shaped, linear, elliptic, and turning curve types, similar to the study conducted 3 years earlier by Liu et al., ${ }^{16}$. The linear curve $(24.8 \%)$ in the current study was completely different from the straight projection $(12.2 \%)$ observed by Ozturk et al., in 2012, and the other curves were not similar to their findings ${ }^{15}$. In the study by Liu et al., ${ }^{16}$ elliptic curves $(48.5 \%)$ were the most frequent, and spoon-shaped curves $(29.3 \%)$ were the subsequently most frequent pathway. The most common pathway found in the current study was the elliptical curve $(62.2 \%)$. In the study conducted by Jung and Cho in Korea in $2014^{18}$, elliptical curves $(64.7 \%)$ were the most common, followed by linear curves $(22.9 \%)$ and spoon curves $(6.9 \%)$. This result is nearly similar to the current study in which the elliptic curve was $62.2 \%$, followed by the linear curves $(24.8 \%)$ and the spoonshaped curves $(7.9 \%)$. These results indicated that in Yemeni patients there is more space for implant placement, because the elliptical and spatula curves can provide more space for implant placement than the linear curves ${ }^{18}$. In the current study, invisible mandibular canals were discovered in 198 (21.3\%) of the examined sites in the first molar region, in 85 $(11 \%)$ in the second molar region, and in only 6 $(0.64 \%)$ in the third molar region. This finding is consistent with the fact that the visibility of the mandibular canal may differ between patients and between different areas of the lower jaw as described by Oliveira Santos et al., ${ }^{2}$. The current incidence of invisible mandibular canals $(21.3 \%)$ was lower than that reported by Klinge et al., ${ }^{19}$ as the mandibular canal were not visible in $36.1 \%$ of the panoramic radiographs. Current study rate $(21.3 \%)$ is also lower than that of Naitoh et al., ${ }^{20}$ who reported that in panoramic images, the canal was completely invisible. While current study rate was roughly similar to that reported by Jung and $\mathrm{Cho}^{18}$ in that the mandibular canal was not invisible in $22.7 \%$ of the sites examined 
in the first molar region on panoramic radiographs. Additionally, Lindh et al., ${ }^{21}$ in Sweden accounted that the mandibular canal of the specimen cadavers was obviously visible in $25 \%$ of the panoramic radiographs. In this study, on the panoramic radiographs, the mandibular canal was obviously visible in $13.5 \%$ of the examined positions in the first molar region, $19.3 \%$ of the positions examined in the second molar region and $47 \%$ of the sites inspected in the third molar region. Imaging of the mandibular canal wall on the panoramic images was linked to the bone density in the alveolar region $^{20}$. Decreased visibility of the mandibular canal wall on a panoramic radiograph may reveal decreased integrity of the mandibular canal wall and reduced bone trabeculation. The percentages of clearly visible mandibular canals were highest in spoon-shaped curves. The current study result is comparable to that reported by Jung and Cho ${ }^{18}$. What's more the current study results showed that visibility of the mandibular canal in the third molar region was better than that in the first molar region (Table 2). This result is similar to that reported previously ${ }^{18-21}$.

\section{CONCLUSION}

In conclusion the elliptical curves along the path of the mandibular canal were the most present, while a decrease in the ratio of the two types of spoon curve and turning curve was observed. It was found that spoon curve was significantly more common among males than females. It was also found that the visibility of this canal is less in the first molar region than in the third molar region, that's mean the visibility of the mandibular canal increased in more distal regions of the canal.

\section{AUTHOR'S CONTRIBUTION}

This research work is part of a research work under the direction of Al-Kasem Mohammed Abbas. The panoramic radiography images were carefully examined by Nashwan Yahya Al-Shamahi, the professor of radiology, with the help of other authors. All authors assisted with editing the manuscript.

\section{ACKNOWLEDGMENTS}

The authors would like to acknowledge Ammar Dental Clinics, Sana'a, Yemen which supported this work.

\section{CONFLICT OF INTEREST}

No conflict of interest associated with this work.

\section{REFERENCES}

1. Greenstein G, Cavallaro J, Tarnow D. Practical application of anatomy the dental implant surgeon. J Perio 2008; 11: 837839. https://doi.org/10.1902/jop.2008.080086

2. Oliveira-Santos C, Capelozza AL, Dezzoti MS, et al. Visibility of the mandibular canal on CBCT cross-sectional images. J Appl Oral Sci 2011; 19: 240-3.

https://doi.org/10.1590/S1678-77572011000300011
3. Escoda-Francoli J, Canalda-Sahli C, Soler A, et al. Inferior alveolar nerve damage because of overextended endodontic material: a problem of sealer cement biocompatibility? J Endod 2007; 33: 1484-9. https://doi.org/10.1016/j.joen.2007.09.003

4. Tsuji Y, Muto T, Kawakami J, Takeda S. Computed tomographic analysis of the position and course of the mandibular canal: relevance to the sagittal split ramus osteotomy. Int J Oral Maxillofac Surg 2005; 34: 243-6. https://doi.org/10.1016/j.ijom.2004.06.001

5. Kamrun N, Tetsumura A, Nomura Y, et al. Visualization of the superior and inferior borders of the mandibular canal: a comparative study using digital panoramic radiographs and cross-sectional computed tomography images. Oral Surg Oral Med Oral Pathol Oral Radiol 2013; 115: 550-7.

https://doi.org/10.1016/j.oooo.2013.01.001

6. Worthington P. Injury to the inferior alveolar nerve during implant placement: a formula for protection of the patient and clinician. Int J Oral Maxillofac Implants 2004; 19: 731-4. PMID: 15508990

7. Kieser JA, Paulin M, Law B. Intrabony course of the inferior alveolar nerve in the edentulous mandible. Clin Anat 2004; 17: 107-11. https://doi.org/10.1002/ca.10196

8. Bertl K, Heimel P, Reich KM, Schwarze UY, Ulm C. A histomorphometric analysis of the nature of the mandibular canal in the anterior molar region. Clin Oral Investig 2014; 18 : 41-7. https://doi.org/10.1007/s00784-013-0961-z.

9. Anderson LC, Kosinski TF, Mentag PJ. A review of the intraosseous course of the nerves of the mandible. J Oral Implantol 1991; 17: 394-403.PMID: 1813647

10. Carter RB, Keen EN. The intramandibular course of the inferior alveolar nerve. J Anat 1971; 108: 433-40.

11. Denio D, Torabinejad M, Bakland LK. Anatomical relationship of the mandibular canal to its surrounding structures in mature mandibles. J Endod 1992; 18: 161-5. https://doi.org/10.1016/S0099-2399(06)81411-1

12. Wadu SG, Penhall B, Townsend GC. Morphological variability of the human inferior alveolar nerve. Clin Anat 1997; 10: 82-7. https://doi.org/10.1002/(SICI)10982353(1997)10:2<82: $A I D-C A 2>3.0 . C O ; 2-V$

13. Gowgiel JM. The position and course of the mandibular canal. J Oral Implantol 1992; 18: 383-5. PMID: 1298823

14. Bas sa O, Dilek OC. Assessment of the risk of perforation of the mandibular canal by implant drill using density and thickness parameters. Gerodontol 2011; 28: 213-20. https://doi.org/10.1111/j.1741-2358.2009.00362.x

15. Ozturk A, Potluri A, Vieira AR. Position and course of the mandibular canal in skulls. Oral Surg Oral Med Oral Pathol Oral Radiol 2012; 113: 453-8. https://doi.org/10.1016/j.tripleo.2011.03.038

16. Liu T, Xia B, Gu Z. Inferior alveolar canal course: a radiographic study. Clin Oral Implants Res 2009; 20: 1212-8. https://doi.org/10.1111/j.1600-0501.2009.01736.x

17. Heasman PA. Variation in the position of the inferior dental canal and its significance to restorative dentistry. J Dent 1988; 16: 36-9. https://doi.org/10.1016/0300-5712(88)90102-9

18. Yun-Hoa Jung Yun-Hoa, Cho Bong-Hae. Radiographic evaluation of the course and visibility of the mandibular canal. Imaging Sci Dent 2014; 44: 273-8. https://doi.org/10.5624/isd.2014.44.4.273

19. Klinge B, Petersson A, Maly P. Location of the mandibular canal: comparison of macroscopic findings, conventional radiography, and computed tomography. Int J Oral Maxillofac Implants 1989; 4: 327-32. PMID: 2639861

20. Naitoh M, Katsumata A, Kubota Y, Hayashi M, Ariji E. Relationship between cancellous bone density and mandibular canal depiction. Implant Dent 2009; 18: 112-8. https://doi.org/10.1097/ID.0b013e318198da7e

21. Lindh C, Petersson A, Klinge B. Measurements of distances related to the mandibular canal in radiographs. Clin Oral Implants Res 1995; 6: 96-103. https://doi.org/10.1034/j.16000501.1995.060205.x 